\title{
Main tendencies in modern psychology
}

\author{
Elena Shopsha ${ }^{1}$, Tatiana Vakulich ${ }^{2}$ \\ IAPM, Kyiv, Ukraine
}

\begin{abstract}
Introduction. With the development of psychology as a science, with usage of psychological knowledge in various fields of human activity specific field of knowledge gradually became isolated and independent. Each of the areas of psychological knowledge has certain objects and methods of study peculiarities of mental activity depending on the conditions in a particular area of human life and activities... However, all areas of psychological knowledge require knowledge of psychology that studies the psychology of methodological issues, the nature of psychological phenomena, patterns of development and progression of cognitive psychological processes.
\end{abstract}

Purpose of this article is to highlight main tendencies in modern psychology development

Results. The last two centuries the development of psychology is closely related with achievement of philosophical thought and progress of science. Materialist interpretation of nature and the nature of mental phenomena has caused the appearance of dialectical materialism philosophy and the development of the doctrine about the reflex nature of the psyche. The basic principles in the national psychology are the principles of integrity mental life of the individual, the relationship between the mental processes and the properties of the individual in learning and education, social conditioning of mental life

Conclusions. There are two-way of communication between the psychology and other sciences: in some cases, the psychology uses the knowledge of other sciences to solve the problems, in other cases -the other science uses psychological knowledge to explain or resolve certain issues.

Keywords. Psychology, behaviorism, psychoanalyses, cognitive psychology

Introduction. With the development of psychology as a science, with usage of psychological knowledge in various fields of human activity specific field of knowledge gradually became isolated and independent. 
There are general psychology, age, educational, social, genetic, engineering, military, medical, legal, sports. Comparative psychology, industrial psychology, art, pathopsychology. Due to space flight appeared a special branch of psychology - cosmic psychology.

Each of these areas of psychological knowledge has certain objects and methods of study peculiarities of mental activity depending on the conditions in a particular area of human life and activities, and their claims to moral and psychological qualities of the individual. However, all areas of psychological knowledge require knowledge of psychology that studies the psychology of methodological issues, the nature of psychological phenomena, patterns of development and progression of cognitive psychological processes, individual characteristics of the human psyche, her feelings and will, temperament, character and ability. In an age of scientific and technological progress and social psychologists were attracted by the problems Labour Psychology and Social Psychology.

Purpose of this article is to highlight main tendencies in modern psychology development

Main results. The last two centuries the development of psychology is closely related with achievement of philosophical thought and progress of science. Materialist interpretation of nature and the nature of mental phenomena has caused the appearance of dialectical materialism philosophy and the development of the doctrine about the reflex nature of the psyche (Maksymenko, 2008). The philosophy of pragmatism had led to behaviorism in American psychology or behavioral science (Crossley, 2009). German psychologists M. Vertheymer, W. Keller, K. Koffka, K. Lewin put forward the idea of structural psychology on the basics of special studies. The main points were to recognize the primary primate structure, integral formations which define properties and functions separate parts that make up an integrated mental activity. Research in psychopathology and psychiatry necessitated to study the role and effect of unconscious factors that determine the needs and desires of the individual and its behavior. This resulted the psychoanalytic tendency in psychology ( $\mathrm{Z}$. Freud) (Frankl, 2018).

Behaviorism denies the consciousness as a subject of psychology. The subject of behaviorism is the study of behavior as external reactions of the body to stimul. Behavior, according to behaviorists, formed as a result of unconscious selection of physical movements as reactions to stimuli. The most important in the behavior - are skills. Thinking is refered by behaviorists to speech and language skills. The leading point in the study they consider - 
training, during which the necessary skills are acquired, herewith understanding of purpose, content and process of learning underestimated.

The basic principle of the structural psychology is the integrity of mental activity that is not the sum of individual mental processes, but the specific structure with inherent of specific properties in it which are not derived from the properties of individual elements of mental life. On the contrary, the properties of the structure as a whole determine the properties of its individual elements. Psychoanalysis closely related to Freud's theory of the prevalence of mental activity of the individual unconscious, instinctive inclinations. According to psychoanalysts, the source of human activity is a deeply instinctive, biologically determined aspirations. This aspiration penetrates from the subconsciousness to the consciousness, becoming a source of human activity, originally directed the actions and behavior. The particular importance psychoanalysts have about the sexual attraction. The basic principles in the national psychology are the principles of integrity mental life of the individual, the relationship between the mental processes and the properties of the individual in learning and education, social conditioning of mental life.

\section{Cognitive mental processes of the individual.}

Cognitive activity - a process reflected in human brain objects and phenomena. Displaying reality in human consciousness may occur at the level of sensory and abstract knowledge. Sensory perception characterized in that the objects and phenomena of the objective world directly act on the senses of man - his sight, hearing, smell, tactile and other analyzers and appear in cord. This form of understanding reality are cognitive mental processes of sensation and perception. The impression produced by sensations and perceptions, carry information about the external characteristics and properties of objects, creating a sensual experience of man. The highest form of man's knowledge of reality is an abstract knowledge of what is going on with the processes of thinking and the imagination. In the developed form of these cognitive processes unique to the person who has the mind and mental activity reveals activity. The essential feature of thought and imagination is the indirect nature reflect their reality, due to the use of previously acquired knowledge, experience, opinions, construction of hypotheses and so on. The object of knowledge in the processes of thinking and imagination are internal, not directly data in sensations properties of objects, patterns of phenomena and processes. Important role in human cognitive activity plays a memory that uniquely reflects, captures and reproduces what appears in consciousness in the process of learning. 
An important feature of cognitive activity is emotional and volitional processes that motivate a person to action, volitional acts. Knowledge objects and phenomena of objective reality, mental life is all cognitive processes. The basis for intellectual knowledge of the world, no matter how difficult it was, is perceptual knowledge. However, perception, memory, reproduction and other processes are not possible without the participation of mental activity, emotions and volitional intentions. But each of these processes has certain laws and acts the mental activity or as a top or as a subsidiary.

Feeling - cognitive mental process mapping in the human brain specific properties of objects and phenomena in their direct effects on the senses of man. The feeling - this is the easiest mental process, the primary form of orientation of a living organism in the environment. Begins with a sense of human cognitive activity. Using different analyzers it selects, accumulates information about the objective reality of their own subjective states and on the basis of received impressions produces adequate conditions of ways to respond to internal and external influences (Seligman, 2002). Sense organs - the only channels through which the outside world enters the mind of man. Reflecting the objective properties of objects and phenomena that exist in the sense of consciousness as a subjective image of the objective world. This feature sensations caused, on the one hand, the most natural feeling as the product reflectance of the brain, and the other - the mental structure of personality that feels. For the typical feelings of positive or negative emotional connotation. Pleasant or unpleasant feelings signal a positive or negative effect of stimulus and cause the appropriate action on it. The vital role of Gnostic and feelings are very important because they are the only source of our knowledge of the external world and about ourselves.

\section{Physiological basis of feelings.}

The doctrine of higher nervous activity reveals the scientific foundations of natural feelings. IM Sechenov and Pavlov for his research showed that feeling - a kind of reflex action, which is the physiological basis for neural processes that occur as a result of the influence of stimuli on the senses or analyzers. Analyzer - the authority of animal, including human, body, analyzing the surrounding reality and distinguish it certain types of energy: visual analyzer isolates light energy or vibrations of electromagnetic waves, hearing - the sounds, ie fluctuations in air gustatory, olfactory - chemical properties of substances, skin thermal and mechanical properties of objects and phenomena that cause certain sensations. Each analyzer is peripheral, analyzing part, or receptor, ie sensory organ, the purpose of which is the separation of the surrounding reality, light, sound, smell and other properties. The 
other part of it - leading the way from the receptor to central analyzer, located in the brain. In the central part of the analyzer distinguish its core, clusters of sensory cells, and scattered off the cages. The core of the analyzer, as noted by Pavlov (Schneider, Längle, 2012), provides a subtle analysis and synthesis of excitations coming from the receptor. This allows stimuli differentiated by features, quality and intensity. Scattered cells perform a rough analysis of such a distinguished musical sounds from noise, perform fuzzy distinction of colors, smells.

Organic violation of any part of the analyzer - peripheral, or central leadership - or cause blindness or deafness, or loss of smell, taste, etc., depending on which analyzer violated. If disturbed only the central part of the analyzer, there is a lack of understanding of what they heard and saw, although feeling a light or sound. Physiological basis simplest sensations and sensitivity in the early stages of life is definitely innate reflex activity of the nervous system. More complex feelings are caused by conditional reflex analytic-synthetic activity of the brain.

Conclusions. There are two-way of communication between the psychology and other sciences: in some cases, the psychology uses the knowledge of other sciences to solve the problems, in other cases -the other science uses psychological knowledge to explain or resolve certain issues.

Intersubjective communication of psychology and other sciences contribute to their mutual development and application in practice. Psychology contributes to the development of data based on biology, including anatomy and physiology, the study of higher nervous activity. In turn, the psychological data are widely used in medicine, particularly in psychiatry

\section{References}

Frankl, V. (2018). The Doctor and the Soul: From Psychotherapy to Logotherapy. Kharkiv: Family Leisure Club. (In Ukrainian)

Maksymenko, S. D. (2008). Generic psychology. (изд. 3rd). Kyiv: Center of educational literature

Michele L. Crossley. (2009). Introducing narrative psychology. Philadelfia: Open University Press

Schneider K, Längle A (2012) The renewal of humanism in psychotherapy: Summary and conclusion. Psychotherapy, 49 (4), 480-481

Seligman, M. (2002). Positive psychology, positive prevention, and positive therapy. In C. Snyder \& S. Lopez (Eds). Handbook of positive psychology. New York: Oxford, 3-9 